\title{
Effects of sibutramine and rimonabant in rats trained to discriminate between $22-$ and 2 -h food deprivation
}

\author{
David C. Jewett • Thomas W. Hahn • Travis R. Smith • \\ Britta L. Fiksdal • Jason M. Wiebelhaus • \\ Andrew R. Dunbar • Catherine R. Filtz • \\ Noah L. Novinska • Allen S. Levine
}

Received: 2 June 2008 / Accepted: 20 September 2008 / Published online: 15 October 2008

(C) Springer-Verlag 2008

\begin{abstract}
Objective The objective of the study was to evaluate whether sibutramine and rimonabant, drugs that decrease food intake in human and non-human animals, affect the discriminative stimulus effects associated with acute food deprivation ("hunger").

Materials and methods Rats were trained to discriminate between 22- and 2-h food deprivation in a two-lever choice procedure. After rats acquired the discrimination, subjects were food-restricted for $22 \mathrm{~h}$ and administered with sibutramine $(0.32-10 \mathrm{mg} / \mathrm{kg}$, p.o.) or rimonabant $(0.32-10 \mathrm{mg} / \mathrm{kg}$, s.c.) before a generalization test session.

Results Sibutramine $(3.2 \mathrm{mg} / \mathrm{kg})$ produced significant decreases in 22-h deprivation-appropriate responding, response rates (resulting in lever pressing rates similar to those following 2-h food deprivation), and food intake measured $1 \mathrm{~h}$ after the generalization test. A larger sibutramine dose eliminated responding and significantly reduced food intake. Rimonabant did not alter the discriminative stimulus effects of 22-h food deprivation, but rimonabant did significantly reduce both response rates and food intake.

Conclusion Sibutramine appears to decrease food intake by reducing hunger sensations associated with food deprivation. In contrast, rimonabant does not alter the discrimination of acute food deprivation. The use of food-deprivation
\end{abstract}

D. C. Jewett $(\bowtie) \cdot$ T. W. Hahn • T. R. Smith • B. L. Fiksdal J. M. Wiebelhaus $\cdot$ A. R. Dunbar $\cdot$ C. R. Filtz $\cdot$ N. L. Novinska Department of Psychology, University of Wisconsin-Eau Claire, Eau Claire, WI, USA

e-mail: jewettd@uwec.edu

\section{A. S. Levine}

College of Food, Agricultural and Natural Resource Sciences, University of Minnesota,

St. Paul, MN, USA discrimination techniques may be useful in identifying the role of specific neuroactive compounds in eating stimulated by a sense of hunger and may aid in medication development for more effective treatments for obesity and other eating-related conditions.

Keywords Sibutramine - Drug discrimination .

Operant behavior $\cdot$ Rimonabant $\cdot$ Food intake $\cdot$ Feeding

\section{Introduction}

Obesity is a leading cause of premature illness and death in the United States. Currently, about one third of adults in the United States are obese (Ogden et al. 2006). Worldwide, more than 800 million people are overweight, and 300 million are obese. This obesity pandemic has resulted in major efforts to develop anorectic drugs. Very few drugs have been developed for obesity treatment, and those that are approved have only limited success. One reason might be that humans eat for many reasons other than "hunger," which we define as nutrient seeking or eating for energy needs. Most obesity drugs target eating driven by energy needs. However, humans also eat for reasons other than hunger. For example, after a satiating large meal, people often ingest desserts high in sugar and fat, likely due to their rewarding properties.

Sibutramine is an anorectic drug that is used widely for the treatment of obesity. It was approved in the United States in 1997 and in the European Union in 1999 (Luque and Rey 1999). Sibutramine is a norepinephrine and serotonin reuptake inhibitor (Gundlah et al. 1997). Sibutramine is less effective as a dopamine reuptake inhibitor and did not generalize to D-amphetamine in rats trained to discriminate D-amphetamine $(0.5 \mathrm{mg} / \mathrm{kg}$, i.p.) from saline (Buckett et al. 
1988). Sibutramine reduces food intake in humans (Weintraub et al. 1991) and non-humans (Jackson et al. 1997a, b). In randomized, double-blind, placebo-controlled studies, sibutramine produced an average placebo-subtracted weight loss of less than $5 \%$ (Hansen et al. 2001).

The endocannabinoid circuits have also been thought to be involved in food intake regulation. Rimonabant, a CB1receptor antagonist (Rinaldi-Carmona et al. 1994), decreases food intake in laboratory animals (Colombo et al. 1998), and more recently has been shown to decrease intake in humans (Heshmati et al. 2001). The double-blind trials demonstrated that rimonabant decreases weight in human subjects by $4-6 \mathrm{~kg}$. As was found with sibutramine, rimonabant produced an average placebo-subtracted weight loss of less than 5\% (Pi-Sunyer et al. 2006). Rimonabant has been shown to produce discriminative stimulus effects using a discriminated taste avoidance procedure (Järbe et al. 2004, 2008), and rimonabant antagonizes the discriminative stimulus effects of THC and other $\mathrm{CB}_{1}$ agonists (Järbe et al. 2001; Mansbach et al. 1996; Wiley et al. 1995a, b).

The mechanism by which these drugs decrease intake is not clear. To test whether hunger is directly involved in the decrease in eating behavior associated with sibutramine and rimonabant, we asked rats to report their hunger status using an operant behavior, discrimination procedure in which rats were trained to discriminate between 22- and 2-h acute food deprivation. Several groups of investigators have used discrimination methodology to train rats that were chronically deprived to recognize the difference between two levels of food deprivation. Corwin et al. trained rats maintained at approximately $80 \%$ of their freefeeding weight to discriminate between food consumed 22 or $3 \mathrm{~h}$ before experimental sessions. Corwin et al. reported that the satiety peptide cholecystokinin (CCK) or ingestion of sweetened condensed milk induced effects similar to food consumption occurring $3 \mathrm{~h}$ before a test session, whereas D-amphetamine and fenfluramine did not reliably produce effects similar to 3-h food ingestion (Corwin et al. 1990). This suggests that CCK produced in effects that resembled a food-satiated state, rather than a food-deprived state. Using a similar methodology in animals that were not chronically restricted, we found that when rats foodrestricted for only $2 \mathrm{~h}$ were centrally injected with orexigenic agents neuropeptide Y (NPY) or ghrelin, rats responded on the lever associated with a 22-h food deprivation (Jewett et al. 2006). This suggests that internal stimuli associated with NPY or ghrelin resembled stimuli produced by $22 \mathrm{~h}$ of food deprivation. Thus, one might conclude that central injection of NPY or ghrelin results in hunger.

We wondered to what extent this behavioral assay might be useful in helping to identify potential pharmacotherapies for obesity and other eating-related conditions. In the present study, we assessed the ability of sibutramine and rimonabant to reduce the discriminative stimulus effects of 22-h food deprivation.

\section{Materials and methods}

\section{Subjects}

Experimentally naïve male Sprague Dawley rats (Harlan, Madison, WI, USA), approximately 90 days old and weighing $250-275 \mathrm{~g}$ at the beginning of the experimental procedures, served as subjects. Rats were individually housed in polycarbonate cages under a 12:12 light/dark cycle (lights on at 8:30 A.M.). Food (Harlan Teklad rodent chow, Madison, WI, USA) and water were continuously available unless otherwise stated. Subjects were maintained in accordance with the National Institute of Health Guide for the Care and Use of Laboratory Animals. The University of Wisconsin-Eau Claire Institutional Animal Care and Use Committee approved all experimental procedures.

\section{Apparatus}

Daily discrimination sessions were conducted in eight standard operant conditioning chambers (Med-Associates, St. Albans, VT, USA) equipped with two response levers. Forty-five milligram food pellets (Bio-Serve F\#0021, Frenchtown, NJ, USA) reinforced lever pressing and were delivered by a pellet dispenser into a food pellet trough located between the two response levers. A houselight located in the back panel of the operant conditioning chamber was illuminated during experimental sessions. Operant conditioning chambers were located in ventilated, sound-attenuating cubicles equipped with fans. Experimental contingencies and data recording were executed via Med Associates software and a personal computer located in an adjacent room.

\section{Drugs}

Sibutramine hydrochloride (Tocris Bioscience, Ellisville, MO, USA) was dissolved in water and administered via oral gavage in a volume of $1 \mathrm{ml} / \mathrm{kg}$ using a curved 16gauge feeding needle (Fine Science Tools, Foster City, CA, USA) attached to a 1-ml syringe. The National Institute of Mental Health's Chemical Synthesis and Drug Supply Program generously provided rimonabant (SR-141716). Rimonabant was dissolved in $75 \%$ propolyene glycol and injected s.c. All solutions were administered in a volume of $1 \mathrm{ml} / \mathrm{kg}$. 
Discrimination training procedure

Rats were initially food-deprived to $\sim 85 \%$ of their freefeeding weight and trained to lever press via the method of successive approximations. Initially, a single lever press was reinforced with a $45 \mathrm{mg}$ food pellet (Bio-Serv F\#0021). Response requirements were gradually increased until 15 lever presses (fixed ratio 15 (FR 15)) were required to produce food. When responding reliably occurred to both levers, rats were given free access to food for 3-5 days before discrimination training began. Rats were trained to discriminate between 22- and 2-h acute food deprivation using multiple cycle training. Under 22-h conditions, food was removed $22 \mathrm{~h}$ before the training session. Rats were placed into the operant conditioning chambers $5 \mathrm{~min}$ before the first training cycle. When the first training cycle began, the houselight was illuminated, and 15 left lever presses were reinforced with a $45 \mathrm{mg}$ food pellet under a FR 15 reinforcement schedule. Incorrect (right) lever presses resulted in $8 \mathrm{~s}$ of darkness under a FR 15. Training continued until five reinforcers were earned or $5 \mathrm{~min}$ elapsed. One or more additional training cycles, identical to the first, commenced 30-60 min after the previous training cycle. Under 2-h conditions, the contingencies were reversed. Right lever presses were reinforced, and left lever presses resulted in $8 \mathrm{~s}$ of darkness under the FR 15 reinforcement schedule. Conditions were quasi-randomly assigned with the provision that the same training condition (22- or 2-h food deprivation) could not be given for more than two consecutive sessions.

Discrimination training continued until the subject emitted $80 \%$ or greater condition-appropriate responses prior to delivery of the first reinforcer and for the entire training session during all training cycles for eight of ten consecutive daily sessions.

\section{Generalization tests}

Generalization tests were conducted to assess the ability of sibutramine and rimonabant to alter the discriminative stimulus effects of 22-h food deprivation. To ensure discriminative control prior to the drug administration, rats were placed in the operant conditioning chamber $15 \mathrm{~min}$ prior to drug administration. Five minutes later, the first response period began during which only left lever presses were reinforced. No differences in discriminative performance were observed among these sessions conducted approximately 20.75 to $21.5 \mathrm{~h}$ after food was removed and sessions preceded by 22 -h food deprivation. If conditionappropriate behavior occurred during the first response period, sibutramine $(0.32-10 \mathrm{mg} / \mathrm{kg}$, p.o., $30 \mathrm{~min} \mathrm{PT})$, water (p.o., $30 \mathrm{~min} \mathrm{PT}$ ), rimonabant $(0.32-10 \mathrm{mg} / \mathrm{kg}$, s.c., $60 \mathrm{~min} \mathrm{PT}$ ), or vehicle (75\% propylene glycol, s.c., $60 \mathrm{~min}$
PT) was administered before the generalization test session. After drug, water, or vehicle administration, subjects were placed in stainless steel cages with no food or water present. Subjects were returned to the operant conditioning chambers $5 \mathrm{~min}$ before test sessions began.

Effects of water (p.o., $30 \mathrm{~min}$ PT) and 75\% propylene glycol (s.c., 60 min PT) were also assessed under 2-h deprivation conditions using a similar procedure. The only procedural differences were that food was removed $2 \mathrm{~h}$ prior to the generalization test session, the first response period was initiated $30 \mathrm{~min}$ to $1 \mathrm{~h}$ after food was removed (no differences in performance were found among time ranging from 0.5 to $2 \mathrm{~h}$ food deprivation), and during the first response period only right lever presses were reinforced under the FR 15 reinforcement schedule.

During all generalization tests, responses on both levers were reinforced under the FR 15 reinforcement schedule. Generalization tests lasted until the subject earned 5 reinforcers or until 5 min elapsed, whichever occurred first. Immediately after most generalization tests, subjects were placed in stainless steel cages and had access to a preweighed amount of food (approximately $25 \mathrm{~g}$ of Teklad rat chow) placed on the floor of the cage and water available in a bottle attached to the cage. Food and water intake was measured at the end of $1 \mathrm{~h}$. After this period, rats were returned to their home cage and had free access to food and water until $2 \mathrm{~h}$ before the next training session.

Appropriate discriminative performance for at least two training days (one preceded by 22 -h deprivation, one preceded by 2 -h deprivation) was required between generalization tests.

\section{Data analysis}

One-way analysis of variance was calculated (SPSS, Chicago, IL, USA) by assessing the effects of sibutramine or rimonabant compared to control conditions on the discriminative stimulus effects of 22-h food deprivation, lever pressing rate, and food intake. Tukey HSD post hoc tests were performed following significant ANOVA values to determine pairwise differences among conditions. Significant effects were noted if $p<0.05$.

\section{Results}

Rats learned to discriminate between 22- and 2-h food deprivation in a mean of 82 sessions (range 21 to 115 sessions). Sibutramine significantly decreased the discriminative stimulus effects of 22-h food deprivation $\left(F_{(3,44)}=\right.$ 5.63, $p=0.002$, Fig. 1, top panel). Post hoc tests revealed that $3.2 \mathrm{mg} / \mathrm{kg}$ sibutramine significantly reduced the discriminative stimulus effects of 22 -h food deprivation 

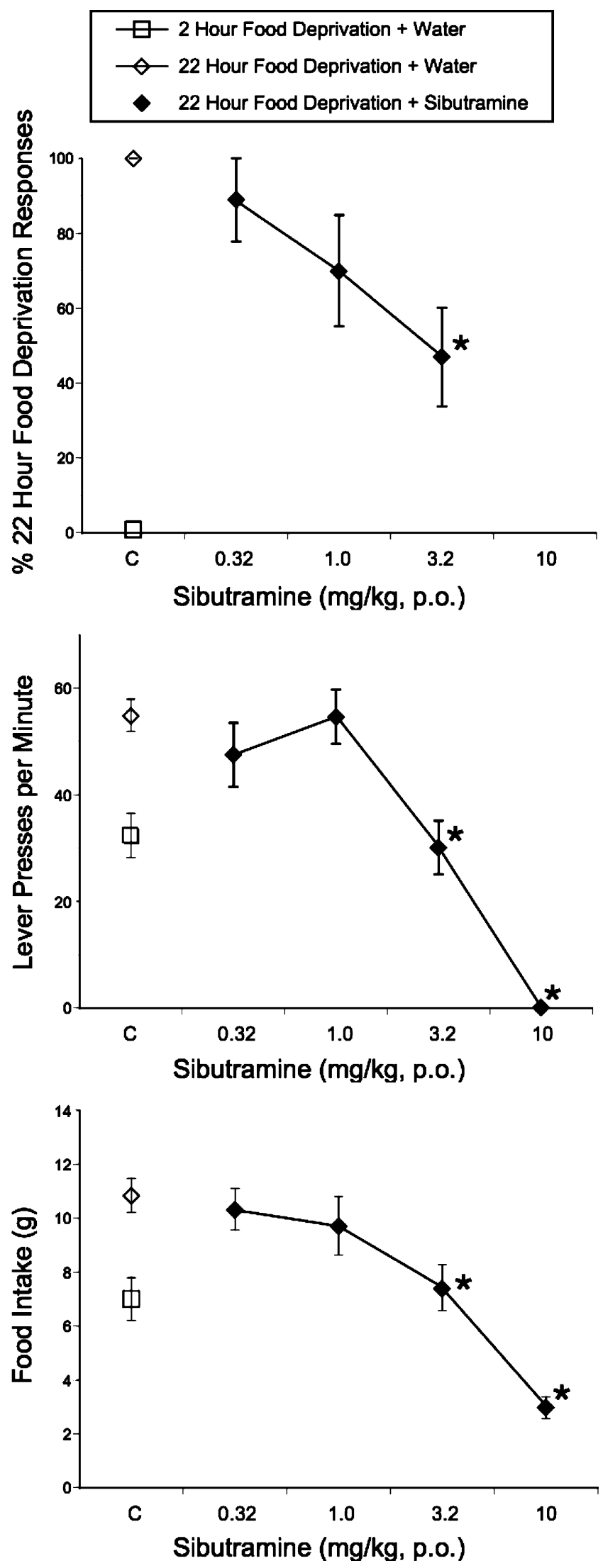

Fig. 1 Effects of sibutramine (closed diamond) on the percentage of 22-h deprivation-appropriate responses (top panel), response rate (middle panel), and 1-h food intake after generalization tests (bottom panel). Points above $C$ depict data following water administration under 2-h (open square) and 22-h (open diamond) conditions. Data points reflect mean values $( \pm \mathrm{SEM})$. Asterisks indicate values significantly different than values obtained under 22-h deprivation with water administration $(p<0.05)$

compared to performance following both water and $0.32 \mathrm{mg} / \mathrm{kg}$ sibutramine administration. Eight of 14 rats given $3.2 \mathrm{mg} / \mathrm{kg}$ sibutramine selected the lever associated with 2 -h food deprivation. Response rates were significantly reduced by sibutramine $\left(F_{(4,47)}=11.30, p<0.001\right.$, Fig. 1 , middle panel). Lever pressing was significantly decreased following 3.2 and $10 \mathrm{mg} / \mathrm{kg}$ sibutramine compared to control response rates (22-h food deprivation preceded by water administration). After $3.2 \mathrm{mg} / \mathrm{kg}$ sibutramine, lever pressing rates were reduced to levels similar to those following 2-h deprivation. Following $10 \mathrm{mg} / \mathrm{kg}$ sibutramine, responding was virtually eliminated and significantly different than response rates following all other conditions. Food intake, measured for $1 \mathrm{~h}$ after the completion of the generalization tests, was assessed in a subset of rats receiving sibutramine. In these subjects food-deprived for $22 \mathrm{~h}$, food intake was significantly reduced by sibutramine $\left(F_{(4,34)}=8.53, p<0.001\right.$, Fig. 1, bottom panel). Food intake following $3.2 \mathrm{mg} / \mathrm{kg}$ sibutramine was reduced compared to control conditions and was similar to food intake under 2-h deprivation conditions. A larger dose of sibutramine $(10 \mathrm{mg} / \mathrm{kg})$ reduced food intake further, and food intake was significantly less than intake following administration of water or 0.32 $1.0 \mathrm{mg} / \mathrm{kg}$ sibutramine.

Unlike sibutramine, rimonabant did not alter the discriminative stimulus effects of 22-h food deprivation at any doses tested $\left(F_{(4,48)}=0.58, p=0.68\right.$, Fig. 2, top panel). Response rates were significantly affected by rimonabant $\left(F_{(4,50)}=3.36\right.$, $p=0.016$, Fig. 2, middle panel). Response rates following $10 \mathrm{mg} / \mathrm{kg}$ rimonabant were significantly less than those following vehicle or rimonabant $(0.32-1.0 \mathrm{mg} / \mathrm{kg})$ administration and similar to rates following 2-h food deprivation. Food intake was significantly reduced by rimonabant administration $\left(F_{(4,47)}=3.66, p=0.011\right.$, Fig. 2 , bottom panel). Rimonabant $(10 \mathrm{mg} / \mathrm{kg})$ significantly decreased food intake compared to control conditions.

\section{Discussion}

The goal of the present experiment was to assess the effects of sibutramine, a serotonin and norepinephrine reuptake inhibitor, and rimonabant, a cannabinoid $\mathrm{CB}_{1}$ antagonist, on the discriminative stimulus effects of 22 -h food deprivation. Both sibutramine and rimonabant decrease food intake in 

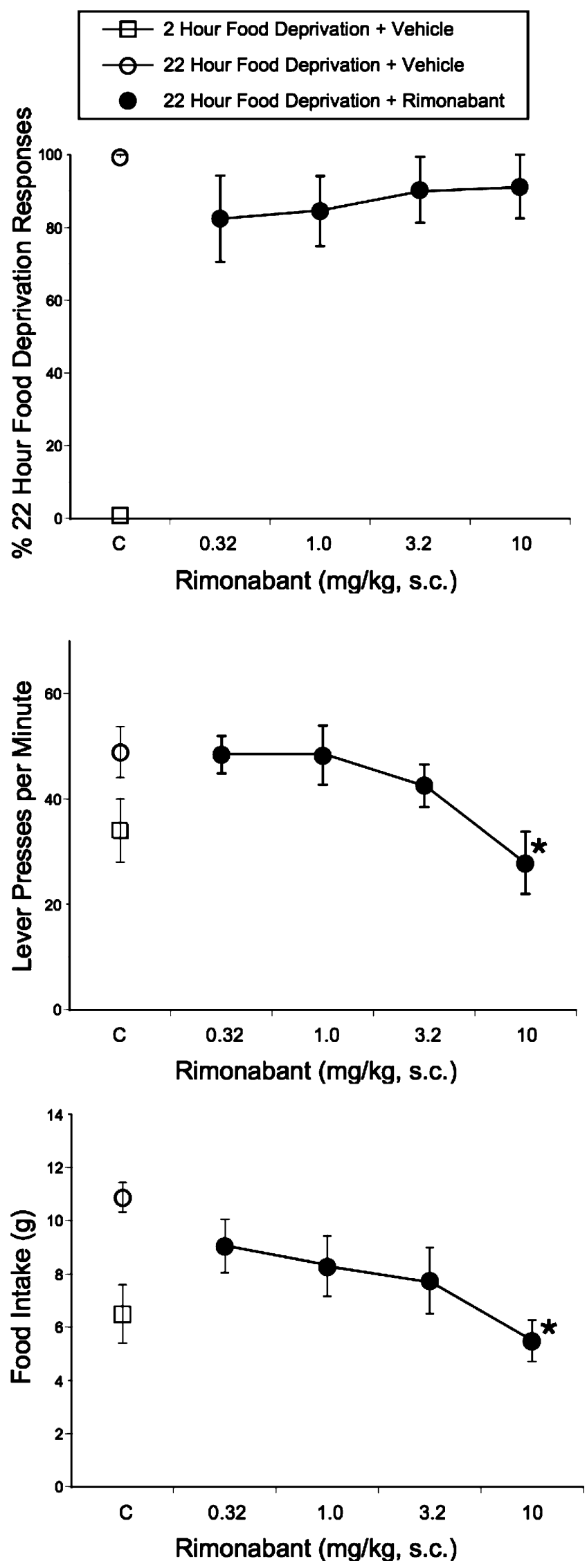

Fig. 2 Effects of rimonabant (closed circle) on the percentage of 22-h deprivation-appropriate responses (top panel), response rate (middle panel), and 1-h food intake after generalization tests (bottom panel). Points above $C$ depict data following vehicle administration under 2-h (open square) and 22-h (open circle) conditions. Data points reflect mean values $( \pm \mathrm{SEM})$. Asterisks indicate values significantly different than values obtained under 22-h deprivation with vehicle administration $(p<0.05)$

non-human animals and decrease hunger, increase satiation, and decrease food intake in humans.

Sibutramine $(3.2 \mathrm{mg} / \mathrm{kg})$ produced a significant decrease in the discriminative stimulus effects produced by $22-\mathrm{h}$ food deprivation. This dose also significantly decreased food intake and reduced response rates to values similar to those following 2-h food deprivation. These findings support the notion that sibutramine works in humans by decreasing appetite and increasing feelings of satiety (Luque and Rey 2002).

These findings indicate that serotonergic and/or noradrenergic activation affects the discrimination of 22-h food deprivation. Further research is required to determine the pharmacological mechanism(s) responsible for this effect and differences between sibutramine, amphetamine, and fenfluramine. Corwin et al. found that the dopamine agonist, Damphetamine and fenfluramine, a serotonin agonist, did not reliably alter the 22-h stimulus in chronically food-restricted animals trained to discriminate between food presented 22 or $3 \mathrm{~h}$ before the experimental session. Previous research assessing the effects of sibutramine and other monoamine reuptake inhibitors on food intake indicated enhancing both serotonin and norepinephrine resulted in a significant reduction in food intake, whereas selective increases of either serotonin or norepinephrine were not effective (Jackson et al. 1997b).

Rimonabant did not alter the discriminative stimulus effects of 22-h food deprivation. This indicates that sibutramine and rimonabant decrease food intake through different mechanisms. Previous research has indicated that rimonabant decreases reward-based feeding. Rimonabant selectively decreased consumption of palatable foods in several different species and feeding paradigms (Arnone et al. 1997; Mathes et al. 2008; Simiand et al. 1998), and rimonabant decreases extracellular dopamine induced by a palatable diet (Melis et al. 2007). While the measures in the discrimination paradigm do not address issues related to the rewarding aspects of food, the lack of effect of rimonabant in the discrimination paradigm indicates that sibutramine and rimonabant affect different feeding mechanisms.

These results are also consistent with an interpretation of our data to this point using the deprivation-discrimination paradigm. Under 2-h deprivation conditions, NPY and ghrelin substituted for the discriminative stimulus effects of 22-h food deprivation, indicating that the paradigm may 
be effective in identifying compounds that work by increasing energy needs. Conversely, sibutramine increases energy expenditure (Hansen et al. 1998, 1999), and in the current study, sibutramine decreased the discriminative stimulus effects of 22-h food deprivation. Future studies will examine the potential interaction between agents that produce discriminative stimulus effects of 22 -h deprivation and agents that decrease these effects, although previous studies have indicated that these compounds can work independently (Brown et al. 2001). In sum, these results indicate that the assessment of the discriminative stimulus effects of acute food deprivation may be a useful behavioral model to identify potential pharmacotherapies for obesity and other eating-related conditions.

Acknowledgments The following sources provided funding for portions of the research: University of Wisconsin-Eau Claire FacultyStudent Collaborative Research Program; University of WisconsinEau Claire Summer Research Experiences for Undergraduates Program; University of Wisconsin-Eau Claire Research and Creative Activity Program; University of Wisconsin-Eau Claire Faculty Sabbatical Leave Program; and Kell Container Corporation Scholarship for Undergraduate Student/Faculty Research (awarded to T.W.H.). We thank Dr. Kathryn L. Hamilton for technical consultation and assistance.

\section{References}

Arnone M, Maruani J, Chaperon F, Thiebot MH, Poncelet M, Soubrie P, Le Fur G (1997) Selective inhibition of sucrose and ethanol intake by SR 141716, an antagonist of central cannabinoid $\left(\mathrm{CB}_{1}\right)$ receptors. Psychopharmacology (Berl) 132:104-106

Brown M, Bing C, King P, Pickavance L, Heal D, Wilding J (2001) Sibutramine reduces feeding, body fat and improves insulin resistance in dietary-obese male Wistar rats independently of hypothalamic neuropeptide Y. Br J Pharmacol 132:1898-1904

Buckett WR, Thomas PC, Luscombe GP (1988) The pharmacology of sibutramine hydrochloride (BTS 54 524), a new antidepressant which induces rapid noradrenergic down-regulation. Prog Neuropsychopharmacol Biol Psychiatry 12:575-584

Colombo G, Agabio R, Diaz G, Lobina C, Reali R, Gessa GL (1998) Appetite suppression and weight loss after the cannabinoid antagonist SR 141716. Life Sci 63:PL113-PL117

Corwin RL, Woolverton WL, Schuster CR (1990) Effects of cholecystokinin, $\mathrm{d}$-amphetamine and fenfluramine in rats trained to discriminate 3 from $22 \mathrm{hr}$ of food deprivation. J Pharmacol Exp Ther 253:720-728

Gundlah C, Martin KF, Heal DJ, Auerbach SB (1997) In vivo criteria to differentiate monoamine reuptake inhibitors from releasing agents: sibutramine is a reuptake inhibitor. J Pharmacol Exp Ther 283:581-591

Hansen DL, Toubro S, Stock MJ, Macdonald IA, Astrup A (1998) Thermogenic effects of sibutramine in humans. Am J Clin Nutr 68:1180-1186

Hansen DL, Toubro S, Stock MJ, Macdonald IA, Astrup A (1999) The effect of sibutramine on energy expenditure and appetite during chronic treatment without dietary restriction. Int $\mathrm{J}$ Obes Relat Metab Disord 23:1016-1024
Hansen D, Astrup A, Toubro S, Finer N, Kopelman P, Hilsted J, Rossner S, Saris W, Van Gaal L, James W, Goulder For The SSGM (2001) Predictors of weight loss and maintenance during 2 years of treatment by sibutramine in obesity. Results from the European multi-centre STORM trial. Sibutramine Trial of Obesity Reduction and Maintenance. Int J Obes Relat Metab Disord 25:496-501

Heshmati HM, Caplain H, Bellisle F (2001) SR141716, a selective cannabinoid $\mathrm{CB}_{1}$ receptor antagonist reduces hunger, caloric intake, and body weight in overweight or obese men. Obes Res 9:70

Jackson HC, Bearham MC, Hutchins LJ, Mazurkiewicz SE, Needham AM, Heal DJ (1997a) Investigation of the mechanisms underlying the hypophagic effects of the 5-HT and noradrenaline reuptake inhibitor, sibutramine, in the rat. $\mathrm{Br} \mathrm{J}$ Pharmacol 121:1613-1618

Jackson HC, Needham AM, Hutchins LJ, Mazurkiewicz SE, Heal DJ (1997b) Comparison of the effects of sibutramine and other monoamine reuptake inhibitors on food intake in the rat. $\mathrm{Br} \mathrm{J}$ Pharmacol 121:1758-1762

Järbe TU, Lamb RJ, Lin S, Makriyannis A (2001) (R)-methanandamide and Delta 9-THC as discriminative stimuli in rats: tests with the cannabinoid antagonist SR-141716 and the endogenous ligand anandamide. Psychopharmacology (Berl) 156:369-380

Järbe TU, Harris MY, Li C, Liu Q, Makriyannis A (2004) Discriminative stimulus effects in rats of SR-141716 (rimonabant), a cannabinoid $\mathrm{CB}_{1}$ receptor antagonist. Psychopharmacology (Berl) 177:35-45

Järbe TU, Li C, Vadivel SK, Makriyannis A (2008) Discriminative stimulus effects of the cannabinoid $\mathrm{CB}_{1}$ receptor antagonist rimonabant in rats. Psychopharmacology (Berl) 198: $467-478$

Jewett DC, Lefever TW, Flashinski DP, Koffarnus MN, Cameron CR, Hehli DJ, Grace MK, Levine AS (2006) Intraparaventricular neuropeptide $\mathrm{Y}$ and ghrelin induce learned behaviors that report food deprivation in rats. NeuroReport 17:733-737

Luque CA, Rey JA (1999) Sibutramine: a serotonin-norepinephrine reuptake-inhibitor for the treatment of obesity. Ann Pharmacother 33:968-978

Luque CA, Rey JA (2002) The discovery and status of sibutramine as an anti-obesity drug. Eur J Pharmacol 440:119-128

Mansbach RS, Rovetti CC, Winston EN, Lowe JA III (1996) Effects of the cannabinoid $\mathrm{CB}_{1}$ receptor antagonist SR141716A on the behavior of pigeons and rats. Psychopharmacology (Berl) 124:315-322

Mathes CM, Ferrara M, Rowland NE (2008) Cannabinoid $\mathrm{CB}_{1}$ receptor antagonists reduce caloric intake by decreasing palatable diet selection in a novel dessert protocol in female rats. Am J Physiol Regul Integr Comp Physiol 295:R67-R75

Melis T, Succu S, Sanna F, Boi A, Argiolas A, Melis MR (2007) The cannabinoid antagonist SR 141716A (Rimonabant) reduces the increase of extra-cellular dopamine release in the rat nucleus accumbens induced by a novel high palatable food. Neurosci Lett 419:231-235

Ogden CL, Carroll MD, Curtin LR, McDowell MA, Tabak CJ, Flegal KM (2006) Prevalence of overweight and obesity in the United States, 1999-2004. JAMA 295:1549-1555

Pi-Sunyer FX, Aronne LJ, Heshmati HM, Devin J, Rosenstock J (2006) Effect of rimonabant, a cannabinoid-1 receptor blocker, on weight and cardiometabolic risk factors in overweight or obese patients: RIO-North America: a randomized controlled trial. JAMA 295:761-775

Rinaldi-Carmona M, Barth F, Heaulme M, Shire D, Calandra B, Congy C, Martinez S, Maruani J, Neliat G, Caput D (1994) 
SR141716A, a potent and selective antagonist of the brain cannabinoid receptor. FEBS Lett 350:240-244

Simiand J, Keane M, Keane PE, Soubrie P (1998) SR 141716, a CB cannabinoid receptor antagonist, selectively reduces sweet food intake in marmoset. Behav Pharmacol 9:179-181

Weintraub M, Rubio A, Golik A, Byrne L, Scheinbaum ML (1991) Sibutramine in weight control: a dose-ranging, efficacy study. Clin Pharmacol Ther 50:330-337
Wiley JL, Barrett RL, Lowe J, Balster RL, Martin BR (1995a) Discriminative stimulus effects of CP 55,940 and structurally dissimilar cannabinoids in rats. Neuropharmacology 34:669676

Wiley JL, Lowe JA, Balster RL, Martin BR (1995b) Antagonism of the discriminative stimulus effects of delta 9-tetrahydrocannabinol in rats and rhesus monkeys. J Pharmacol Exp Ther 275:1-6 